\title{
A Systematic Review on the Effectiveness of Palmitoylethanolamide for the Treatment of Pain in Arthrogenic Temporomandibular Joint Dysfunction and Related Disorders
}

\author{
Immanuel Sani ${ }^{1 *}$ and Yaser Hamza ${ }^{2}$ \\ ${ }^{1}$ Musculoskeletal Physiotherapist, King's College London, Guy's Campus, Great Maze Pond, London, United Kingdom \\ ${ }^{2}$ Medical student, King's College London, Guy's Campus, Great Maze Pond, London, United Kingdom
}

*Correspondence author: Immanuel Sani, Musculoskeletal Physiotherapist, King’s College London, Guy's Campus, Great Maze Pond, London, United Kingdom, Tel: +4401634 854187; E-mail: Immanuel.sani@kcl.ac.uk

Received: September 23, 2019; Accepted: September 30, 2019; Published: October 09, 2019;

\begin{abstract}
Arthrogenic temporomandibular joint dysfunction is a prevalent condition often associated with arthralgia. It is also commonly caused by osteoarthritis. Palmitoylethanolamide has been reported to exhibit analgesic, neuroprotective and anti-inflammatory effects in pain pathological conditions. This paper will critically appraise recent evidence on the effectiveness of palmitoylethanolamide for the treatment of pain in arthrogenic temporomandibular joint dysfunction and related disorders. This paper will assess both the magnitude and longevity of the analgesic effect of palmitoylethanolamide.
\end{abstract}

Method: An electronic database search was performed by two independent authors on the following databases: PubMed, Web of Science, Medline and Embase. A total of 23 articles were retrieved including relevant articles from reference lists. After the elimination of duplicates and further eligibility screening, a resultant total of 5 articles were suitable for review. One of these was a retrospective cohort study while the following 4 were randomised clinical trials. There was considerable heterogeneity of primary outcome variables and trial design across all selected studies which did not permit a meta-analysis of results.

Conclusion: Palmitoylethanolamide is effective for the treatment of pain in arthrogenic temporomandibular joint dysfunction and related disorders. However, the longevity of palmitoylethanolamide-induced analgesia remains unclear. Further high-quality trials are warranted to reveal the relative effectiveness of palmitoylethanolamide in comparison to current medication.

Keywords: Arthralgia, Pain, Palmitoylethanolamide, Temporomandibular Joint Dysfunction

\section{Introduction}

The Temporomandibular Joint (TMJ) is one of the most frequently used joints in the body. Over time, normal or parafunctional use can lead to the initiation of degenerative joint disease, [1]. Degenerative joint disease localised to the TMJ is termed: arthrogenic temporomandibular joint dysfunction (A-TMD), according to group III of the RDC/TMD, [2]. Current evidence shows that A-TMD accounts for $30 \%$ of all TMD cases, [3]. A-TMD has considerable global prevalence and accounts for a high proportion of socioeconomic costs, which are typically related with other psychological disorders, such as depression, [4,5]. A-TMD is a growing public health concern due to its debilitating repercussions on essential orofacial functions such as mastication, speaking and swallowing, [6], which in amalgamation with psychological comorbidities can ultimately impede patient quality of life.
Osteoarthritis (OA) is the most common degenerative TMJ disease associated with A-TMD, affecting $50 \%$ of individuals beyond the age of 65 years and existing in adolescents following TMJ trauma, [7,8]. The pathogenesis of OA involves a cascade of aberrant biomechanical alterations in the tissues of the joint that subsequently triggers the immune response. Immune cells instigate an inflammatory response by secreting various inflammatory mediators, [9]. The process is coupled with the activation and release of cartilage degrading factors such as matrix metalloproteinase and prostaglandin $\mathrm{E}$ which further damage the articular cartilage, [10]. This results in articular cartilage degradation and remodelling of the subchondral bone, causing chronic pain with a central sensitisation component in most cases, [11].

Sensory innervation of the TMJ is derived from the mandibular (V3) branch of the trigeminal cranial nerve. The inferior alveolar nerve (a branch of the mandibular nerve) provides sensory innervation 
to the mandibular dental arch, which is itself the third branch of the trigeminal nerve. Therefore, orofacial trauma in the mandibular vicinity can give rise to referred pain in the TMJ, [12].

Current pharmacological treatment of A-TMD quintessentially entails the use of acetaminophen or NSAIDs. Several studies have revealed that acetaminophen provides negligible short-term benefit for patients with OA, [13,14]. NSAIDs have proven to be more effective for pain relief than acetaminophen for patients with arthralgia, $[15,16]$. Despite the superior effectiveness of NSAIDs to acetaminophen, it is well-documented that long-term NSAID overuse has been associated with increased likelihood of adverse side effects such as gastric and cardiovascular complications [17,18]. Considering this, there is an urgent need to develop innovative drugs that produce both significant analgesic effects and minimal side effects.

Palmitoylethanolamide (PEA) is an endogenous $\mathrm{N}$-acylethanolamine and is analogous to the endocannabinoid anandamide, [19] but without psychotropic influences. PEA has been described to induce analgesic, neuroprotective and anti-inflammatory effects in previous studies involving acute and chronic pain states, $[20,21]$. The precise mechanism of action of PEA is not entirely understood, although it has been posited that PEA may interact with peroxisome proliferator-activated receptor (PPAR)- $\alpha$ which exhibits anti-inflammatory effects, [22]. The literature also suggests that PEA mimics an endogenous ligand for the $\mathrm{CB}_{2}$ receptors, [23], which mediates analgesic effects in neuropathic pain states, [24]. The beneficial effects of PEA have been demonstrated in previous studies either alone or in combination with a different drug [25,26]. In this regard, PEA shows promising results for an innovative pharmacological intervention. However, the paucity of knowledge on the duration of the treatment effect derived from PEA warrants further investigation.

This systematic review aims to critically appraise evidence on the effectiveness of PEA for the treatment of pain in arthrogenic temporomandibular joint dysfunction and related disorders. Both the magnitude and longevity of the analgesic effect of PEA will be assessed.

\section{Methods}

This systematic review is grounded upon the recommendations of the PRISMA statement for systematic reviews, [27].

\section{Data Sources and Search Strategy}

An electronic literature search was conducted on the following databases: PubMed, Web of Science, Medline and Embase up to 14 July 2019, with no restrictions on the publication language or date. The key words inputted in this search were: Arthralgia; pain; palmitoylethanolamide and temporomandibular joint dysfunction. (Table S1) depicts the search terms and strategy (see supporting information). The reference list of provisionally selected studies was manually reviewed to identify studies that were absent from the electronic databases and were then included for further screening. We methodically contacted corresponding authors for studies with partial data [28-32].

\section{Eligibility Criteria and Study Selection}

The inclusion and exclusion criteria for study selection are itemised in (Table 1). Titles and abstracts of all studies found from the database search were manually screened for compatibility with the inclusion criteria by two review authors. Data was extracted based on the nature of participants' TMD, type of intervention, comparison or control interventions, relevant outcome variables and study design.

Table 1. Eligibility criteria for study selection.

\begin{tabular}{|c|c|c|}
\hline & Inclusion criteria & Exclusion criteria \\
\hline Participants & $\begin{array}{l}\text { 1. Active A-TMD } \\
\text { 2. Osteoarthritis } \\
\text { 3. Orofacial trauma }\end{array}$ & $\begin{array}{l}\text { 1. Mixed TMD } \\
\text { 2. Myogenic TMD }\end{array}$ \\
\hline $\begin{array}{l}\text { Experimental } \\
\text { Intervention }\end{array}$ & PEA & Non-PEA treatment \\
\hline $\begin{array}{l}\text { Comparison or control } \\
\text { intervention }\end{array}$ & $\begin{array}{l}\text { 1. NSAIDs } \\
\text { 2. Opiates } \\
\text { 3. Muscle relaxants } \\
\text { 4. Analgesics } \\
\text { 5. Benzodiazepines } \\
\text { 6. Anticonvulsants }\end{array}$ & N/A \\
\hline $\begin{array}{l}\text { Primary outcome } \\
\text { variable }\end{array}$ & Pain & Non-pain related \\
\hline Study design & All designs & N/A \\
\hline
\end{tabular}

Notes: N/A: Not applicable, NSAID: Non-steroidal anti-inflammatory drugs PEA: Palmitoylethanolamide, TMD: Temporomandibular joint dysfunction

After selecting studies based on eligibility criteria, the kappa coefficient $(\mathrm{k})$ for agreement among the reviewers was $\mathrm{k}=0.937$.

\section{Data collection}

A standardised proforma was used to systematically cumulate data on the type of study design, participant characteristics, intervention and control or comparison characteristics, primary outcome variables, and follow-up intervals if present. Additional pertinent data such as the funding source, potential conflict of interests between authors and reported risk of bias was also collected.

\section{Risk of Bias and Quality Assessment}

The risk of bias (RoB) and subsequent methodological quality of the selected studies was ascertained according to the Cochrane Risk of Bias Tool, [33] by two independent reviewers. The tool was used to assess bias from the following domains: random sequence generation, allocation concealment, blinding of participants and personnel, blinding of outcome assessment, incomplete outcome data, selective reporting, and other bias. Each domain was scored as either 'low', 'high' or 'unclear' RoB for each respective study. The overall RoB in a study was categorized as high quality if all criteria were scored as 'low' RoB; moderate quality if only one criterion was scored as 'high' RoB or if two criteria were scored as 'unclear' RoB and Low quality if two or more criteria were scored as 'high' RoB or if at least three criteria possessed 'unclear' RoB, [33]. 
Discrepancies in overall RoB classifications for each study between reviewers was settled by providing supporting reasons and a final consensus was reached. After critical appraisal of selected studies, there was a final agreement of $\mathrm{k}=0.884$ between reviewers.

\section{Patient involvement}

No patients with A-TMD were involved in the conceptualisation or completion of this review, assessment of outcomes, interpretation of findings, or editing of the manuscript.

\section{Results}

As shown in (Figure 1), 21 studies were obtained from the initial electronic database search and 2 additional studies were later found from a manual search of reference lists. After the elimination of duplicates, screening titles, abstracts and full texts, 5 studies with a cumulative total of 227 trial participants were included in this review.

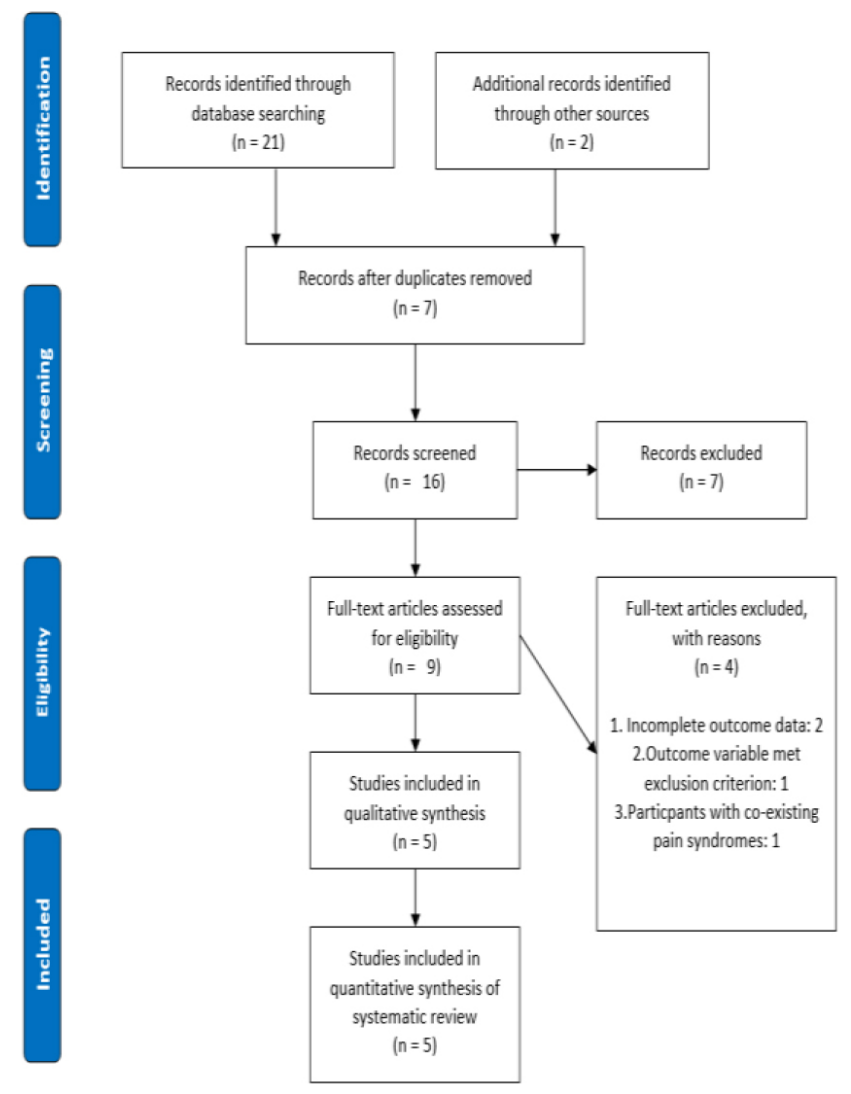

Figure 1. PRISMA flowchart of study selection.

\section{Study characteristics}

Details on the key characteristics of the 5 eligible studies are provided in (Table 2). A total of 4 randomised clinical trials (RCTs) and 1 retrospective cohort study were retrieved. Of the 185 participants who were randomised, 108 (58\%) were assigned to receive PEA. The mean sample size was 45.4 (range: $24-111$ ). The mean age of participants in human trials was 40.5 years (range: 18-60) and the median proportion of male individuals was $41.6 \%$ (range: $33-47 \%$ ). No follow -up assessment was detected in 4 studies, yet a single study, [28] showed a follow-up period ranging from 3 to 7 days.
The overall quality was moderate for 3 studies (60\%) and low quality for 2 studies (40\%). (Figure 2) shows the cumulative RoB on each RoB criterion presented as a percentage across all selected studies. More specifically, the risk of selection bias (sequence generation and allocation concealment) was unclear for $30 \%$ of studies and low for $70 \%$ of studies. The risk of performance bias (blinding of patients and investigators) and detection bias (blinding of investigators) was low for $20 \%$ and $10 \%$ of studies, respectively. Lastly, $60 \%$ of trials presented with low RoB for incomplete outcome data. Overall, we have interpreted the results of the included studies with moderate confidence in the quality of the studies in question. (Table 3 ) shows a comprehensive assessment of the RoB for each study. Figure 2 depicts the proportion of RoB for each criterion across all selected studies.

\section{Arthrogenic TMD}

Three studies, [29,31,32] addressed the effectiveness of PEA on A-TMD. The participant eligibility criteria used for 2 of the 3 studies, $[29,31]$ were based on group III of the Research Diagnostic Criteria for TMD (RDC/TMD). All 3 studies concluded that PEA is useful for attenuating A-TMD-related pain and few studies revealed that PEA is superior to common NSAIDs in pain reduction, [29,31]. All 3 studies concluded that PEA is an effective treatment for TMJ pain associated with A-TMD. Further details are shown in Table 2.

\section{Osteoarthritis}

One study, [30] investigated the effectiveness of PEA for the treatment of pain in patients with knee OA. As previously mentioned, the data from this trial is applicable to A-TMD due to the similar pathophysiology and symptomatology of both conditions. Steels et al, [30] implemented comprehensive eligibility criteria which only included patients with moderate knee OA and were medically stable. The study ultimately concluded that PEA is effective for pain attenuation in knee $\mathrm{OA}$, and as such this finding is generalisable to A-TMD.

\section{Orofacial pain}

One study, [28] investigated the effectiveness of PEA following bilateral tooth extraction. Again, as previously stated, the data from this trial was deemed to be pertinent to A-TMD and provide further evidence to support or negate the effectiveness of PEA in pain reduction. The participant eligibility criteria were based on signs and symptoms as well as radiographic dentition assessment. This study also concluded that PEA demonstrated an ameliorative effect on orofacial pain.

\section{Adverse events}

The medical literature shows that PEA is well-tolerated by human subjects. A total of 2 separate mild adverse events were reported by 2 individual participants treated with $300 \mathrm{mg}$ of Normast ${ }^{\mathrm{mm}}$ after an impacted molar tooth extraction, [28]. This represents an incidence risk of $0.88 \%$ across the pooled sample size of selected studies (227) and is therefore insignificant. One patient reported a transient episode of drowsiness after Normast ${ }^{\mathrm{tw}}$ treatment. Another patient reported a 2-3-hour episode of cardiac palpitations on the third day of the trial. 
Sani I, Hamza Y (2019) A Systematic Review on the Effectiveness of Palmitoylethanolamide for the Treatment of Pain in Arthrogenic Temporomandibular Joint Dysfunction and Related Disorders

This arose 1 hour after Normast ${ }^{\text {Tit }}$ administration, and subsequently the patient dropped out of the trial after this incident. This patient's medical history showed evidence of cannabinoid use. Hence, it is therefore logical to suggest that the symptom reported by this patient was due to the synergic effect of PEA and tetrahydrocannabinol. The low rate of adverse events for PEA is encouraging, however we cannot definitively conclude whether the low incidence of adverse events depicts a true low risk based on the few published studies.

Table 2. Characteristics of selected studies.

\begin{tabular}{|c|c|c|c|c|c|}
\hline $\begin{array}{l}\text { Author(s), date, } \\
\text { country }\end{array}$ & Participant characteristics & PEA Intervention & $\begin{array}{c}\text { Comparison/ Control } \\
\text { intervention }\end{array}$ & Assessment interval(s) & Outcome variable(s) \\
\hline $\begin{array}{l}\text { Bacci et al, } 2011 \\
\text { Italy }\end{array}$ & $\begin{array}{l}\text { Condition: Bilateral impacted } \\
\text { lower third molar extractions } \\
\text { Treatment }+ \text { control group } \\
\text { combined: } \\
\mathrm{n}=30 \\
\text { Total M: F = N/D } \\
\text { Mean age of total participants = } \\
24.00 \pm 21.21\end{array}$ & $\begin{array}{l}\text { m-PEA tablet } \\
\text { Dose: } 300 \mathrm{mg} \times 2 \text { tablets per } \\
\text { day for } 15 \text { days }\end{array}$ & $\begin{array}{l}\text { Unilateral impacted lower } \\
\text { third molar extraction } \\
\text { without m-PEA }\end{array}$ & $\begin{array}{l}\text { Measurement at baseline, } \\
\text { Follow-up at } 3 \text { days } \\
\text { post-surgery and } 7 \text { days } \\
\text { post-surgery }\end{array}$ & Pain assessed by VAS \\
\hline $\begin{array}{l}\text { Marini et al, } 2012 \\
\text { Italy }\end{array}$ & $\begin{array}{l}\text { Condition: TMJ osteoarthritis } \\
\text { and arthralgia } \\
\text { 1.PEA group: } \mathrm{n}=12 \\
\text { 2.Control group: } \mathrm{n}=12 \\
\text { Total M: } \mathrm{F}=8: 16 \\
\text { Mean age of total participants }= \\
39.00 \pm 15.00\end{array}$ & $\begin{array}{l}\text { PEA tablet } \\
\text { Dose: } 300 \mathrm{mg} \text { in morning and } \\
600 \mathrm{mg} \text { in evening for days. } \\
\text { Then } 300 \mathrm{mg} \times 2 \text { per day for } \\
7 \text { days. }\end{array}$ & $\begin{array}{l}\text { Ibuprofen } \\
\text { Dose: } 600 \mathrm{mg} \mathrm{x} 3 \text { per day } \\
\text { for } 14 \text { days }\end{array}$ & $\begin{array}{l}\text { Measurement at baseline, } \\
\text { day } 1 \text { before treatment } \\
\text { and day } 14 \text {. No follow-up. }\end{array}$ & Pain assessed by VAS \\
\hline $\begin{array}{l}\text { Bartolucci et al, } \\
2018 \\
\text { Italy }\end{array}$ & $\begin{array}{l}\text { Condition: Induced TMJ } \\
\text { inflammation in rats } \\
\text { 1.Sham group: } \mathrm{n}=10 \\
\text { 2.Sham + PEA: } \mathrm{n}=10 \\
\text { 3.CFA + vehicle: } \mathrm{n}=10 \\
\text { 4.CFA + PEA: } \mathrm{n}=10 \\
\text { Total M: } \mathrm{F}=\mathrm{N} / \mathrm{A} \\
\text { Mean age of total participants: } \\
\text { N/A }\end{array}$ & $\begin{array}{l}\text { Intraperitoneal m-PEA } \\
\text { administration in: } \\
\text { 1.Sham +PEA group } \\
\text { 2.CFA + PEA group } \\
\text { Dose: } 10 \mathrm{mg} / \mathrm{kg}\end{array}$ & $\begin{array}{l}\text { 1.Sham group (Saline } \\
\text { injection into left TMJ } \\
\text { capsule) } \\
\text { 2.CFA + vehicle group } \\
\text { ( } 50 \mu 1 \text { of CFA injection } \\
\text { into left TMJ capsule) }\end{array}$ & $\begin{array}{l}\text { Measurement at } 24 \text { hours } \\
\text { and } 72 \text { hours post- } \\
\text { injection respectively. No } \\
\text { follow-up. }\end{array}$ & $\begin{array}{l}\text { Mechanical allodynia } \\
\text { threshold }\end{array}$ \\
\hline $\begin{array}{l}\text { Marini et al, } 2018 \\
\text { Italy }\end{array}$ & $\begin{array}{l}\text { TMJ osteoarthritis and arthralgia } \\
\text { 1.um-PEA + celecoxib group: } \\
\mathrm{n}=6 \\
\text { 2.um-PEA group: } \mathrm{n}=6 \\
\text { Total M: } \mathrm{F}=5: 7 \\
\text { Mean age of total participants: } \\
42.50 \pm 24.75\end{array}$ & $\begin{array}{l}\text { um-PEA tablet + celecoxib } \\
\text { tablet } \\
\text { Dose: um-PEA } 600 \mathrm{mg} \mathrm{x} 1 \\
+ \text { celecoxib } 200 \mathrm{mg} \text { in the } \\
\text { morning and } 200 \mathrm{mg} \text { in the } \\
\text { evening for first } 4 \text { days. } \\
\text { Then, } 600 \mathrm{mg} \text { um-PEA daily } \\
\text { for } 14 \text { days }\end{array}$ & $\begin{array}{l}\text { um-PEA tablet ( } 600 \mathrm{mg} \text { for } \\
14 \text { days) }\end{array}$ & $\begin{array}{l}\text { Measurement at baseline } \\
\text { and each day for } 14 \text { days. } \\
\text { No follow-up. }\end{array}$ & Pain assessed by VAS \\
\hline $\begin{array}{l}\text { Steels et al, } 2019 \\
\text { Australia }\end{array}$ & $\begin{array}{l}\text { Knee osteoarthritis } \\
\text { 1.300mg PEA group: } \mathrm{n}=36 \\
\text { 2.600mg PEA group: } \mathrm{n}=35 \\
\text { 3.Placebo group: } \mathrm{n}=40 \\
\text { Total M: } \mathrm{F}=\mathrm{N} / \mathrm{D} \\
\text { Mean age of total participants: } \\
57.00 \pm 26.87\end{array}$ & $\begin{array}{l}\text { 1.300mg PEA tablet group } \\
\text { Dose: } 150 \mathrm{mg} \text { x } 2 \text { per day for } \\
8 \text { weeks } \\
2.600 \mathrm{mg} \text { PEA tablet group } \\
\text { Dose: } 300 \mathrm{mg} \text { x } 2 \text { per day for } \\
8 \text { weeks }\end{array}$ & $\begin{array}{l}\text { Placebo group (received } \\
\text { maltodextrin x } 2 \text { per day } \\
\text { for } 8 \text { weeks) }\end{array}$ & $\begin{array}{l}\text { Measurement at baseline, } \\
\text { day } 2 \text {, week } 1 \text {, week } 4 \\
\text { and week } 8 . \text { No follow- } \\
\text { up. }\end{array}$ & Pain assessed by NRS \\
\hline
\end{tabular}

Notes: CFA - Complete freund's adjuvant, N/D - Not detected, NRS - Numerical rating scale, VAS - Visual analogue scale, m-PEA - Micronised palmitoylethanolamide, PEA Palmitoylethanolamide, um-PEA - Unmicronised PEA. 
Sani I, Hamza Y (2019) A Systematic Review on the Effectiveness of Palmitoylethanolamide for the Treatment of Pain in Arthrogenic Temporomandibular Joint Dysfunction and Related Disorders

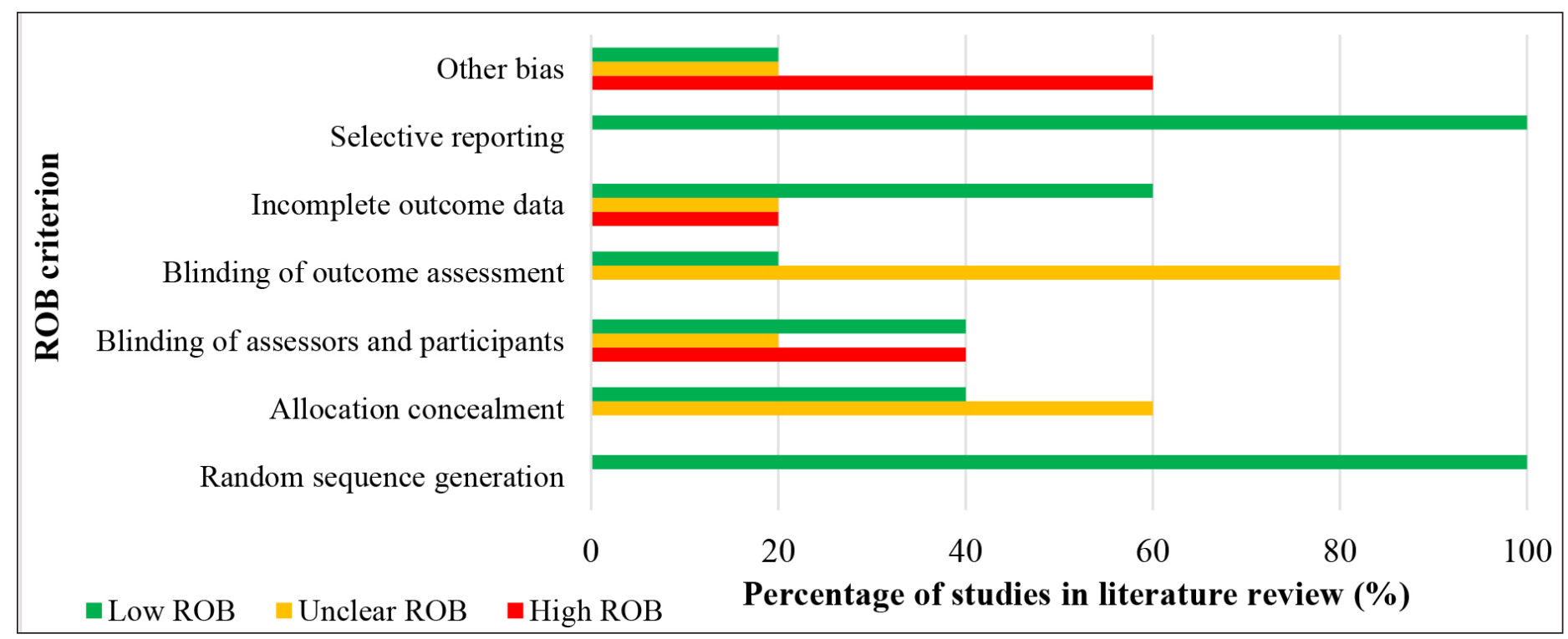

Figure 2. A cumulative risk of bias graph representing the reviewer's findings on each risk of bias criterion presented as a percentage across all selected studies in the literature review.

Table 3. Methodological quality appraisal of selected studies and associated risk of bias.

\begin{tabular}{|c|c|c|c|c|c|c|c|c|}
\hline $\begin{array}{c}\text { Study } \\
\text { (Author and year) }\end{array}$ & $\begin{array}{c}\text { Random sequence } \\
\text { generation }\end{array}$ & $\begin{array}{c}\text { Allocation } \\
\text { concealment }\end{array}$ & $\begin{array}{c}\text { Blinding of } \\
\text { assessors and } \\
\text { participants }\end{array}$ & $\begin{array}{c}\text { Blinding } \\
\text { of outcome } \\
\text { assessment }\end{array}$ & $\begin{array}{c}\text { Incomplete } \\
\text { outcome data }\end{array}$ & $\begin{array}{l}\text { Selective } \\
\text { reporting }\end{array}$ & $\begin{array}{c}\text { Other } \\
\text { bias }\end{array}$ & $\begin{array}{c}\text { Overall } \\
\text { quality rating }\end{array}$ \\
\hline Bacci et al, 2011 & Low & Unclear & High & Unclear & Low & Low & Low & Moderate \\
\hline Marini et al, 2012 & Low & Low & Low & Low & Low & Low & Unclear & Moderate \\
\hline Bartolucci et al, 2018 & Low & Unclear & High & Unclear & High & Low & High & Low \\
\hline Marini et al, 2018 & Low & Unclear & Unclear & Unclear & Unclear & Low & High & Low \\
\hline Steels et al, 2019 & Low & Low & Low & Unclear & Low & Low & High & Moderate \\
\hline
\end{tabular}

Notes: 'High', 'low' or 'unclear' risk of bias RoB.

\section{Discussion}

\section{Principal findings}

In the present systematic review, we merged data from 5 studies involving 227 participants. These studies generally used a small sample size, with the largest consisting of 111 patients. Based on RCTs at moderate and low risk of bias, we discovered moderate to high quality evidence that PEA has a significant effect on pain reduction in A-TMD. This finding was also corroborated by a single animal study, [32]. However, the longevity of this analgesic effect remains inconclusive due to the dearth of trials that include a follow-up period.

\section{PEA effectiveness}

This systematic review shows that offering PEA to patients with A-TMD and associated conditions, may prove to be an effective pharmacological intervention to enhance clinical outcomes. All 5 studies in this review concluded that PEA was indeed effective for pain reduction.
Firstly, Bacci et al, [28] found that on the third day after extraction, the mean VAS recorded by the Normast ${ }^{\mathrm{tm}}$ group was $3.8 \pm 3.09 \mathrm{~cm}$, whereas the control group showed a change of $5.5 \pm 2.42 \mathrm{~cm}$. Similarly, this trend continued at the 7-day follow-up interval with the mean VAS for the Normast ${ }^{\text {tix }}$ group inferior compared to the control group at $1.0 \pm 1.82 \mathrm{~cm}$ and $1.5 \pm 2.18 \mathrm{~cm}$ respectively. Despite this positive finding, the authors did not report a power calculation and the study used a small sample size of 30 participants, of which only 26 completed the protocol. Consequently, the small sample size may have increased the prospect of detecting a false-positive (Type II error) result, which reduces the power of the study. Although a strength of this study, was the implementation of a rigorous screening protocol and assessment for homogeneity of baseline characteristics which may have diminished the effect of confounding bias on the summative results.

In addition, the results of the study by Marini et al, [31] showed that VAS scores decreased to $37.42 \pm 0.36 \mathrm{~mm}$ and $7.69 \pm 0.16 \mathrm{~mm}$ in 
the ibuprofen and PEA groups respectively by the end of treatment. The difference between the mean VAS values at baseline and those obtained at treatment cessation between both groups was statistically significant $(\mathrm{p}=0.0001)$. However, a limitation of this study was the short trial duration (14 days) and as such, there is uncertainty whether the favourable findings are sustainable in treated individuals in the long-term.

Another study by Marini et al, [29] showed a gradual decline in pain intensity following the administration of Celecoxib + um-PEA. Mean VAS scores reduced from $71.08 \pm 8.7 \mathrm{~mm}$ at baseline to $5.5 \pm 2.1$ $\mathrm{mm}$ at treatment cessation, so the decrement in mean VAS score over time was vastly significant $(p=0.0001)$. However, the authors failed to report or potentially omitted data on the results for the um-PEA alone group and as such, it is difficult to deduce if um-PEA caused the statistically significant results observed. Yet, other similar studies have discovered significant results in favour of PEA. Thus, in this case, um-PEA was likely to have induced the significant analgesic effect in this trial.

Furthermore, Steels et al, [30] revealed that NRS pain scores were significantly reduced in the $300 \mathrm{mg}$ PEA group $(\mathrm{p}=0.0005)$ and 600 mg PEA group $(\mathrm{p}<0.001)$ compared to the placebo group. In the $300 \mathrm{mg}$ PEA group, there was a considerable increase in the number of participants that no longer experienced pain during the study (baseline, $\mathrm{n}=8$; week $1, \mathrm{n}=15$; week $4, \mathrm{n}=17$; and week $8, \mathrm{n}=21$ ). A similar trend was also observed for the $600 \mathrm{mg}$ PEA group (baseline, $\mathrm{n}=9$; week $1, \mathrm{n}=14$ ); week $4, \mathrm{n}=23$; and week $8, \mathrm{n}=24$ ). Overall, both groups demonstrated a $163 \%$ and $167 \%$ increase in absolute pain resolution respectively. However, the placebo group showed negligible dissimilarity in the number of patients that no longer experienced pain during the trial (baseline, $\mathrm{n}=13$; week $1, \mathrm{n}=14$; week $4, \mathrm{n}=11$; week $8, \mathrm{n}=11$ ). This discrepancy highlights the marked effectiveness of PEA in pain attenuation for arthralgia.

The findings in the animal study by Bartolucci et al, [32] were considered with less weighting in this review due to both the limited validity of the trial design and the use of an unconventional outcome variable which made comparisons with other studies challenging. Despite this, the study did provide ancillary evidence as to the effectiveness of PEA. The authors reported that CFA-injected rats (induced A-TMD) treated with $\mathrm{m}-\mathrm{PEA}$, displayed reduced orofacial mechanical allodynia in comparison to the CFA-vehicle group. A criticism of this study resides in the difficulty to extrapolate these findings to human subjects due to the significant disparity in pharmacokinetics of PEA and dosage regimens in both species, conceivably leading to variation in effectiveness and toxicity of the drug. However, a benefit of this study is that it supports the superiority of m-PEA over um-PEA which will ultimately inform future human trials.

\section{Strengths and limitations of this study}

This systematic review is the first to investigate the effectiveness of PEA for the treatment of pain in A-TMD and related disorders. This review possesses several strengths. Firstly, we conducted a rigorous and extensive literature search, contacted several authors, and meticulously examined the reference lists of all provisional studies to find relevant articles. Therefore, the likelihood that a trial was missed, in the presence of an already limited evidence base, was low. Additionally, most included studies involved participants with similar characteristics that would be observed in clinical practice. Therefore, the results from this review is generalizable to the clinical population.

However, we acknowledge several limitations in this review. Solely studies published in peer-reviewed journals and in the English language were selected for review which may predispose our findings to publication bias. There may also be the potential for confirmation bias, owing to the selection and interpretation of data which validates pre-existing hypotheses. However, the utilisation of a systematic search strategy, methodological quality appraisal and independent reviewers may assuage this matter. Another short coming was the inclusion of trials whereby a placebo control group was absent, lacked blinding or possessed obscure blinding protocols. Such drawbacks may perhaps cause the gauged benefits of PEA to be understated or overestimated. Additionally, the significant heterogeneity in trial design, outcome variables and PEA formulation did not permit a meta-analysis, and therefore the clinical significance of PEA could not be assessed.

\section{Implications for future research}

The clinical data regarding the effectiveness and tolerability of PEA are promising, yet further randomised clinical trials are necessary to reveal the clinical significance of PEA on a larger scale. Due to the shortcomings of the included trials in this systematic review, we recommend several developments for future research on this topic: 1) Use randomised, placebo-controlled trial design to facilitate unbiased measurements on the effectiveness, tolerability and longevity of PEA ; 2) Consistent and complete reporting of adverse events in all study groups; 3) Conduct cost-effectiveness analysis such that the qualityadjusted life years can be established and inform policy makers ; 4) Implement trial follow-up assessments to assess the longevity or potential long-term side effects of PEA treatment; 5) Ensure trials are sufficiently powered, with statistically satisfactory homogeneity in outcome variables and participant characteristics to permit future meta-analyses; and 6) Conduct head-to-head comparisons with current medication to discover the relative effectiveness of PEA and further inform policy makers.

\section{Conclusion}

This systematic review imparts introductory evidence that PEA is effective for the treatment of pain in A-TMD and related disorders. The findings from this review are promising as PEA demonstrates a superior analgesic effect to some NSAIDs, yet the longevity of this effect remains indeterminate. Further high-quality trials with followup assessments are warranted to compare the effectiveness of PEA relative to various medications currently used for the treatment of pain in A-TMD.

\section{Acknowledgement}

We thank the authors of selected studies who provided clarification of their trials for this systematic review. 
Sani I, Hamza Y (2019) A Systematic Review on the Effectiveness of Palmitoylethanolamide for the Treatment of Pain in Arthrogenic Temporomandibular Joint Dysfunction and Related Disorders

\section{Abbreviations}

A-TMD: Arthrogenic temporomandibular joint dysfunction

M-PEA: $\quad$ Micronised PEA

NSAID: Non-steroidal anti-inflammatory drug

OA: $\quad$ Osteoarthritis

PEA: Palmitoylethanolamide

PRISMA: Preferred Reporting Items for Systematic Reviews and Meta-Analyses

RCT: $\quad$ Randomised clinical trial

RDC/TMD: Research Diagnostic Criteria for Temporomandibular joint disorders

RoB: $\quad$ Risk of bias

TMD: $\quad$ Temporomandibular joint dysfunction

TMJ: $\quad$ Temporomandibular joint

Um-PEA: Unmicronised PEA

VAS: $\quad$ Visual analogue scale

Table S1. Literature search terms and strategy

\begin{tabular}{|l|l|}
\hline \multicolumn{1}{|c|}{ Database (search date) } & \multicolumn{1}{c|}{ Search } \\
\hline PubMed (14 July, 2019) & $\begin{array}{l}\text { (palmitoylethanolamide OR } \\
\text { Palmitoylethanolamide OR PEA) AND } \\
\text { (temporomandibular joint dysfunction OR TMD } \\
\text { OR temporomandibular joint disc disorder) } \\
\text { AND (pain OR arthralgia) }\end{array}$ \\
\hline $\begin{array}{l}\text { Web of science (14 July, } \\
\text { 2019) }\end{array}$ & $\begin{array}{l}\text { (Palmitoylethanolamide OR PEA) AND } \\
\text { (temporomandibular joint dysfunction OR } \\
\text { temporo-mandibular disorder TMD OR TMJ) }\end{array}$ \\
\hline Medline (14 July, 2019) & $\begin{array}{l}\text { (Palmitoylethanolamide OR PEA) AND (TMD } \\
\text { OR TMJ OR temporo-mandibular disorder OR } \\
\text { temporomandibular joint dysfunction) }\end{array}$ \\
\hline Embase (14 July, 2019) & $\begin{array}{l}\text { \#1 TMJ OR TMD OR temporomandibular AND } \\
\text { joint OR 'temporo-mandibular' AND joint OR } \\
\text { 'temporo-mandibular' AND disorder } \\
\text { \#2 'palmitoylethanolamide' OR PEA AND } \\
\text { 'Palmitoylethanolamide' } \\
\text { \#1 and \#2 }\end{array}$ \\
\hline
\end{tabular}

\section{References}

1. Cairns B (2010) Pathophysiology of TMD pain-basic mechanisms and their implications for pharmacotherapy. Journal of Oral Rehabilitation 37: 391-410.

2. Dworkin SF, LeResche L (1992) Research diagnostic criteria for temporomandibular disorders: review, criteria, examinations and specifications critique. JCraniomandib Disord 6: 301 .

3. Manfredini D, Guarda-Nardini L, Winocur E, Piccotti F (2011) Research diagnostic criteria for temporomandibular disorders: a systematic review of axis I epidemiologic findings. Oral Surgery, Oral Medicine, Oral Pathology, Oral Radiology, and Endodontology 112: 453-462.

4. Giannakopoulos NN, Keller L, Rammelsberg P, Kronmüller KT, Schmitter M (2010) Anxiety and depression in patients with chronic temporomandibular pain and in controls. J Dent 38: 369-376. [crossref]

5. Gil-Martínez A, Grande-Alonso M, La Touche R, Lara-Lara M, López-López A, et al. (2016) Psychosocial and Somatosensory Factors in Women with Chronic Migraine and Painful Temporomandibular Disorders. Pain Res Manag 2016: 3945673. [crossref]
6. de Melo Júnior PC, Aroucha JMCNL, Arnaud M, Lima MGS, Gomes SGF, et al. (2019) Prevalence of TMD and level of chronic pain in a group of Brazilian adolescents. PLoS One 14: e0205874. [crossref]

7. Zhang Y, Jordan JM (2010) Epidemiology of osteoarthritis. Clin Geriatr Med 26: 355-369. [crossref]

8. Wieland H, Michaelis M, Kirschbaum B, Rudolphi K (2005) Osteoarthritis - an untreatable disease? Nature Reviews Drug Discovery 4: 331-344.

9. Kalladka M, Quek S, Heir G, Eliav E (2014) Temporomandibular Joint Osteoarthritis: Diagnosis and Long-Term Conservative Management: A Topic Review. The Journal of Indian Prosthodontic Society 14: 6-15.

10. Tanaka E, Detamore MS, Mercuri LG (2008) Degenerative disorders of the temporomandibular joint: etiology, diagnosis, and treatment. J Dent Res 87: 296 307.

11. Kosek E, Ordeberg G (2000) Abnormalities of somatosensory perception in patients with painful osteoarthritis normalize following successful treatment. European journal of pain 3: 229-238.

12. Dolatabadi M, Lassemi Em (2012) Trauma to the Temporomandibular Joint Following Tooth Extraction via Dental Students. Trauma Monthly 16: 205-205.

13. Machado GC, Maher CG, Ferreira PH, Pinheiro MB, Lin CW, et al. (2015) Efficacy and safety of paracetamol for spinal pain and osteoarthritis: systematic review and meta-analysis of randomised placebo controlled trials. BMJ 350: h1225. [crossref]

14. Bjordal J, Klovning A, Ljunggren A, Slørdal L (2007) Short-term efficacy of pharmacotherapeutic interventions in osteoarthritic knee pain: A meta-analysis of randomised placebo-controlled trials. European Journal of Pain 11: 125-138.

15. Zhang W (2004) Does paracetamol (acetaminophen) reduce the pain of osteoarthritis? a meta-analysis of randomised controlled trials. Annals of the Rheumatic Diseases 63: 901-907

16. Rasmussen S (2018) NSAIDs are superior to paracetamol for osteoarthritic pain and function in a network meta-analysis. BMJ Evid Based Med 23: 40-41. [crossref]

17. Hinz B, Brune K (2004) Pain and osteoarthritis: new drugs and mechanisms. Curr Opin Rheumatol 16: 628-633. [crossref]

18. Farkouh M, Greenberg B (2009) An Evidence-Based Review of the Cardiovascular Risks of Nonsteroidal Anti-Inflammatory Drugs. The American Journal of Cardiology 103: 1227-1237.

19. Lambert D, Vandevoorde S, Jonsson K, Fowler C (2002) The Palmitoylethanolamide Family: A New Class of Anti-Inflammatory Agents? Current Medicinal Chemistry 9: 663-674.

20. Cocito D, Peci E, Ciaramitaro P, Merola A, Lopiano L (2014) Short-term efficacy of ultramicronized palmitoylethanolamide in peripheral neuropathic pain. Pain Res Treat 2014: 854560. [crossref]

21. Skaper SD, Facci L, Fusco M, Della Valle MF (2014) Palmitoylethanolamide, a naturally occurring disease-modifying agent in neuropathic pain. Inflammopharmacology 22: 79-94.

22. Paterniti I, Impellizzeri D, Crupi R, Morabito R (2013) Molecular evidence for the involvement of PPAR-d and PPAR-? in anti-inflammatory and neuroprotective activities of palmitoylethanolamide after spinal cord trauma. Journal of Neuroinflammation 10.

23. Costa B, Comelli F, Bettoni I, Colleoni M (2008) The endogenous fatty acid amide, palmitoylethanolamide, has anti-allodynic and anti-hyperalgesic effects in a murine model of neuropathic pain: involvement of CB1, TRPV1 and PPAR? receptors and neurotrophic factors. Pain 139: 541-550.

24. Wallace V, Segerdahl A, Lambert D, Vandevoorde S (2009) The effect of the palmitoylethanolamide analogue, palmitoylallylamide (L-29) on pain behaviour in rodent models of neuropathy. British Journal of Pharmacology 151: 1117-1128.

25. Passavanti MB, Alfieri A, Pace MC, Pota V, Sansone P, et al. (2019) Clinical applications of palmitoylethanolamide in pain management: protocol for a scoping review. Syst Rev 8: 9. [crossref]

26. Gabrielsson L, Mattsson S, Fowler C (2016) Palmitoylethanolamide for the treatment of pain: pharmacokinetics, safety and efficacy. British Journal of Clinical Pharmacology 82: 932-942.

27. Liberati A, Altman DG, Tetzlaff J, Mulrow C, Gøtzsche PC, et al. (2009) The PRISMA statement for reporting systematic reviews and meta-analyses of studies that evaluate health care interventions: explanation and elaboration. $J$ Clin Epidemiol 62: 1-34. [crossref]

28. Bacci C, Cassetta G, Emanuele B, Berengo M (2011) Randomized Split-Mouth Study on Postoperative Effects of Palmitoylethanolamide for Impacted Lower Third Molar Surgery. ISRN Surgery 1-6.

29. Marini I, Cavallaro J, Bartolucci M, Alessandri-Bonetti A (2018) Can Celecoxib enhance Palmitoylethanolamide's effect in the treatment of Temporo-mandibular arthralgia in osteoarthritis patients? Journal of Translational Science 5.

30. Steels E., Venkatesh R, Steels E, Vitetta G (2019)A double-blind randomized placebocontrolled study assessing safety, tolerability and efficacy of palmitoylethanolamide for symptoms of knee osteoarthritis. Inflammopharmacology 27: 475-485. 
Sani I, Hamza Y (2019) A Systematic Review on the Effectiveness of Palmitoylethanolamide for the Treatment of Pain in Arthrogenic Temporomandibular Joint Dysfunction and Related Disorders

31. Marini I, Bartolucci M, Bortolotti F, Gatto M (2012) Palmitoylethanolamide versus a non-steroidal anti-inflammatory drug for the treatment of temporomandibular inflammatory joint pain. J orofac pain 26: 29-104.

32. Bartolucci M, Marini I, Bortolotti F, Impellizzeri D (2018) Micronized palmitoylethanolamide reduces joint pain and glial cell activation. Inflammation Research 67: 891-901.
33. Higgins JP, Altman DG, Gøtzsche PC, Moher D (2011) Cochrane Bias Methods Group, Cochrane Statistical Methods Group. The Cochrane Collaboration's tool for assessing risk of bias in randomised trials. BMJ 343: 5928.

\section{Citation:}

Immanuel Sani (2019) A Systematic Review on the Effectiveness of Palmitoylethanolamide for the Treatment of Pain in Arthrogenic Temporomandibular Joint Dysfunction and Related Disorders. J Dent Maxillofacial Res Volume 2(4): 1-8. 